\title{
A dinâmica discursiva na sala de aula e a apropriação da escrita
}

\author{
Maria do Socorro Alencar Nunes Macedo* \\ Eduardo Fleury Mortimer ${ }^{* *}$
}

\begin{abstract}
RESUMO: Este trabalho discute, no contexto da teoria sociocultural, alguns elementos que constituem a dinâmica discursiva de uma sala de aula em que a escrita e as normas ortográficas são objetos de ensino-aprendizagem. O vídeo foi usado na coleta de dados e as transcrições, organizadas na forma de episódios de ensino, foram submetidas à análise microgenética. Essa análise permite inferir que o discurso da professora é heterogêneo e encerra uma tensão entre dialogia e univocidade, pois possibilita a participação dos alunos no processo de enunciação ao mesmo tempo que controla a produção de significados unívocos em relação às regras de ortografia. Os dados evidenciam também que os alunos internalizam não só os conteúdos de ensino, mas também aspectos mais gerais do discurso escolar, como regras disciplinares e estratégias metacognitivas de aprendizagem.
\end{abstract}

Palavras-chave: Escrita, discurso, sala de aula, sociocultural, apropriação

Neste trabalho pretendemos discutir alguns elementos que constituem a dinâmica discursiva na sala de aula, no contexto da apropriação dos aspectos ortográficos da escrita. Interessa-nos apreender como os processos interativos e dialógicos entre alunos e professora, e entre os próprios alunos, mediatizam o processo de elaboração conceitual da escrita pelas crianças.

Para tanto, buscamos nos referenciais da Psicologia Histórico-Cultural de Vygotsky e na Teoria da Enunciação de Bakhtin alguns elementos

\footnotetext{
* Pesquisadora da FAE/Ceale/UFMG. E-mail: macedo@horiz.com.br

** Docente e pesquisador da FAE/UFMG. E-mail: emortimer@artsci.wustl.edu
} 
que nos possibilitem compreender e interpretar a dinâmica discursiva nos processos de ensino-aprendizagem. Recorremos também aos trabalhos de pesquisadores contemporâneos que investigam o processo de elaboração conceitual na sala de aula à luz da perspectiva histórico-cultural.

Nessa perspectiva teórica, o conhecimento não resulta da interação direta do sujeito com os objetos, pois essa interação é sempre mediada por instrumentos materiais e simbólicos, entre os quais a linguagem adquire uma importância especial. Nessa ação mediada a participação do outro é fundamental, o que implica considerar que os processos psicológicos emergem das relações e interações entre os sujeitos.

Ao tratar das origens sociais dos processos psicológicos superiores, Vygotsky toma como base a sua lei geral do desenvolvimento cultural. Nas palavras do autor,

Qualquer função, presente no desenvolvimento cultural da criança, aparece duas vezes ou em dois planos distintos. Em primeiro lugar, aparece no plano social, para aparecer, logo, no plano psicológico. Em princípio, aparece entre as pessoas como uma categoria interpsicológica, para logo aparecer na criança como uma categoria intrapsicológica. (1981b, p. 163, apud Werstch 1988, p. 78)

A internalização das formas culturais de comportamento envolve a reconstrução da atividade psicológica tendo como base a operação com signos. As funções psicológicas que emergem e se consolidam no plano da ação entre os sujeitos tornam-se internalizadas, isto é, transformamse para constituir o funcionamento interno. Dessa forma, os processos intramentais não são cópias simples e diretas dos processos intermentais. Ao contrário, a relação entre esses dois processos é a da "transformação genética e da formação de um plano interno da consciência" (Wertsch e Smolka 1994), num movimento de reconstrução e de re-significação da cultura pela ação do sujeito.

Para Bakhtin (1929/1995), o processo de compreensão e de significação só ocorre por meio da produção de contrapalavras vinculadas às palavras do interlocutor.

É como se nós especificássemos, em resposta a cada palavra da enunciação que estamos em processo de entendimento, um conjunto de nossas próprias palavras. Quanto maior o número e o peso dessas 
palavras, mais profundo e substancial será o nosso entendimento (Voloshinov 1973, p.102, citado por Wertsch 1991, p. 54).

Nesse sentido, o sujeito se constitui pela internalização dos signos que circulam nas interações verbais e extraverbais de que participa. Segundo Bakhtin, os enunciados só podem ser entendidos no interior da cadeia de interação verbal, uma vez que não carregam significados literais, mas são sempre dinâmicos e dependentes do já dito e das respostas que antecipam. Uma conseqüência dessa visão dialógica é que os significados dependem da forma como as várias vozes, representando diferentes horizontes conceituais e visões de mundo dos interlocutores, interagem nessa cadeia de significação.

Dessa forma, julgamos que, para que o processo de compreensão e constituição do conhecimento efetive-se na sala de aula, é fundamental que o professor permita as contrapalavras dos alunos, dialogando com eles, possibilitando a interanimação de vozes e, conseqüentemente, a geração de novos significados.

Edwards e Mercer (1988) apontam que o conhecimento elaborado e sistematizado em uma sala de aula tem características de um conhecimento comum que vai sendo compartilhado pelo professor e pelos alunos. Os pesquisadores identificaram em suas pesquisas, alguns elementos que caracterizam as interações discursivas entre o professor e os alunos:

(i) o discurso da sala de aula é estruturado basicamente num padrão denominado IRF (iniciação do professor, resposta do aluno, feedback do professor); a iniciação do professor se dá através de perguntas elicitativas; os autores descrevem o feedback basicamente como uma avaliação, pelo professor, da resposta do aluno. Mortimer e Machado (1997) mostram que o feedback pode assumir outras formas além de avaliar a resposta dada pelo aluno. Por exemplo, pode constituir-se de novas perguntas que possibilitem o desenvolvimento da elaboração conceitual pelo aluno.

(ii) normalmente o professor utiliza estratégias discursivas para garantir uma compreensão compartilhada que possibilite a continuidade da elaboração do conhecimento pelos alunos; o professor procura no início de cada aula recuperar com os alunos informações discutidas em aulas anteriores; o professor busca também estabelecer relações entre os conceitos já apropriados pelos alunos e os que estão sendo objetos de discussão numa 
determinada aula; além disso, faz comentários metacognitivos quando algum aluno apresenta dificuldades de compreensão de algum conteúdo ou conceito.

Consideramos, no entanto, que a idéia de conhecimento compartiIhado, na forma como Edwards e Mercer (1988) a empregam, pode estar em contradição com a própria noção de que os significados são polissêmicos e dependentes do contexto de enunciação, de acordo com Bakhtin. Rommetveit (1979) parece oferecer uma solução satisfatória para essa questão, na forma como usa a noção de intersubjetividade. Segundo Rommetveit, uma intersubjetividade perfeita, que a idéia de conhecimento compartilhado parece comportar, seria uma ficção e, portanto, impossível. No entanto, o autor admite que "nós precisamos, inocente e irrefletidamente, admitir a possibilidade de perfeita intersubjetividade para alcançar intersubjetividade parcial no discurso da vida cotidiana" (Rommetveit 1979, p.161, grifos do autor). Assim, o conhecimento compartilhado pode ser interpretado como algo que é tacitamente assumido na sala de aula e que garante a continuidade do processo de significação, apesar de ser algo que não se realiza plenamente.

As formas que o feedback, como parte do padrão IRF, assume em sala de aula, ora avaliativo, ora elaborativo, foram relacionadas por Mortimer e Machado (1997) à noção de dualismo funcional do texto, sistematizada por Lotman (1988, citado por Wertsch 1991). Lotman argumenta que um texto cumpre duas funções básicas: "transmitir significados adequadamente e gerar novos significados" (p. 34). A primeira função é denominada função unívoca e é "melhor preenchida quando os códigos do falante e do ouvinte coincidem o mais completamente possível e, conseqüentemente, o texto tem um grau máximo de univocidade" . A função dialógica tem como objetivo gerar novos significados, possibilitar a produção de contrapalavras, como diria Bakhtin. Nesse sentido, o texto é compreendido não como um elo passivo de transmissão de significados, mas como um instrumento de pensamento. A noção de dualismo funcional do texto, segundo Wertsch (1991), pode também ser relacionada à distinção que Bakhtin faz entre discurso de "autoridade" e discurso internamente persuasivo. $O$ discurso de autoridade parte do pressuposto de que os significados são fixos e não se modificam quando estabelecem contato com outras vozes. Contrastando, o discurso internamente persuasivo é parte nosso e parte do outro e permite a interanimação dialógica. Sua estrutura não é finita, é aberta e pode revelar em cada contexto novas formas de significar.

Em nossa pesquisa, buscamos apreender as características da dinâmica discursiva na sala de aula, a partir das seguintes questões: quais 
os modos de participação do professor e dos colegas no processo de apropriação do conhecimento pelo aluno? Que padrões discursivos estruturam a interlocução entre a professora e os alunos nessa sala de aula? Como os alunos referemse ao discurso do professor nos processos de interlocução e que tipo de feedback - professor utiliza na resposta às dúvidas e questionamentos colocados pelos alunos sobre a língua escrita?

Nossa intenção é caracterizar o discurso escolar produzido pelo professor e pelos alunos como um gênero heterogêneo e contraditório, ainda que esse discurso pareça ter como objetivo a homogeneização dos processos de produção de significados (Mortimer, 1998).

\section{As opções metodológicas}

Apresentamos como possibilidade a utilização metodológica de aspectos da análise microgenética, derivada das proposições metodológicas de Vygotsky (op. cit.), que tem como princípio básico a análise de processos e não de objetos, interpretação e explicação e não descrição de comportamentos.

Alguns pesquisadores ${ }^{1}$ que trabalham com os pressupostos vygotskyanos definiram como análise microgenética a busca de

(...) um caminho para documentar empiricamente a presença (ou não) e o grau de transição do funcionamento interpsicológico para o funcionamento intrapsicológico, durante a solução conjunta de situações problema entre adulto e criança, nos moldes do que Vygotsky denominava "Zona de Desenvolvimento Proximal" (Hickmann e Werstch 1978, pp. 251-253 apud Fontana 1996, p. 32).

Entretanto, a especificidade das formas de interação que ocorrem na sala de aula - interações coletivas e não diádicas (adulto-criança) - impõenos limites para a percepção e o registro empírico do grau de transições microgenéticas pelo aluno, individualmente. Além disso, no episódio selecionado para a análise, não se evidenciam transições entre o funcionamento interpsicológico e o intrapsicológico, já que a tarefa que os alunos estão realizando demanda o uso de conceitos e regras da ortografia já internalizados. Assim, consideramos que nos é possível observar, nesse contexto interacional, apenas o movimento das idéias do grupo sobre as formas ortográficas da escrita e indícios de internalização desses elementos pelas crianças. 
Os dados da pesquisa que deram origem a este trabalho foram organizados na forma de episódios de ensino, compreendidos como um recorte metodológico que resulta em fragmentos, que são parte de um processo mais amplo de elaboração do conhecimento. Foram extraídos de duas aulas gravadas em vídeo no período de abril a junho de 1997. Os episódios escolhidos são aqueles que ajudam a caracterizar a dinâmica das interações discursivas que ocorrem no processo de ensino-aprendizagem (Macedo1998).

O episódio escolhido para análise neste artigo foi subdivido em três seqüências, que são episódios menores e que evidenciam as características da dinâmica discursiva no contexto da apropriação da escrita que nos interessa destacar. A transcrição procura ser fiel ao máximo à linguagem produzida oralmente pelas crianças e pela professora. $\mathrm{Na}$ apresentação do episódio, os turnos de fala foram numerados para facilitar a referência na análise. Além disso, acrescentou-se uma segunda coluna à coluna contendo o texto verbal produzido, na qual se procura registrar elementos não verbais, como gestos, ações, indícios da entonação etc., assim como algumas observações que auxiliem a análise.

\section{O episódio: correção coletiva do texto de Weder. Contextualização}

Os alunos realizaram uma produção de texto individual na aula anterior, a partir de uma seqüência de quadrinhos retirada de uma revista da "Turma da Mônica". A professora normalmente realizava a correção das produções dos alunos no quadro (um texto a cada vez), da seguinte forma: ela transcrevia o texto de um dos alunos preservando a forma como as palavras haviam sido escritas por ele. A correção era feita a cada frase transcrita. O grupo, com a intervenção da professora, ia reescrevendo as palavras na forma correta. O objetivo é possibilitar a construção de um conhecimento instersubjetivo da escrita através de um processo no qual diferentes hipóteses e dúvidas dos alunos são socializadas e problematizadas pela professora.

Ao que parece os alunos já estavam habituados à dinâmica dessas aulas.Portanto, já respondiam positivamente à demanda da professora quando solicitados a participarem na correção do texto do colega. Nessa aula, a professora revela que o texto escolhido foi o de Weder. O episódio selecionado para análise é composto de 84 turnos, correspondentes a mais ou menos 10 minutos da aula, que transcorreu num tempo total de 42 minutos. 


\section{O Episódio}

1- P: Não vou ler todos. Hoje não vou dar conta. Cada Os turnos 1 a 10 dia vou ler uma.

2-Als: Lê a minha! [....]

3-P: Eu vou ler uma que foi a que eu escolhi. Que que eu falei pra vocês? Durante o ano vou "passar" uma de cada um de vocês no quadro. Tem jeito de passar todas de uma vez?

4-Als:Nãão.

5-P: Tem jeito de ler todas de uma vez?

6-P: Primeiro que eu vou ficar atrasada e segundo que vai perder a graça.

8-Al: Não vai dar tempo.

9-P: É não vai dar tempo. Eu escolhi a do Weder. Por que que eu escolhi a do Weder?

10-Al:Pra ir bem mais rápido.

11-P: Enquanto cês tão lendo cada um vai fazer o quê?

12-Als: É ( ...)

13-P: Enquanto eu tô escrevendo cês vão fazer o quê?

14-Als: Lê!

15-P: Ler com atenção e observar o quê?

16-Als: observar a história.

17-P: Observar o que tá errado.

18-P: Olhem, vocês têm que esperar eu "passar" (escrever o título no Quadro) para depois corrigir, tá bem? Vou "passar" linha por linha.

19- P: Ele já começou, tudo bem. Aonde?

20-P: Aqui?

21- Als: Ééé.

22- P: O que ele escreveu?

23- Als: OSU

24- P: O que que tá errado?

25- Al : É dois S.

26- Outro Al : e o U.

27- P: Vou por dois $S$ aqui.

permitem-nos inferir que a professora busca explicitar a escolha do texto através de um processo de interlocução em que se resgata algo já negociado anteriormente, evitando a imposição de normas.

18-Ao iniciar a escrita do título do texto (U TOTÓ IO OSU), os alunos começam a intervir, falando ao mesmo tempo.

19-Um aluno aponta para a palavra OSU. A professora volta-se para o aluno que interferiu. Os alunos apontam juntos para a palavra OSU. 20-A professora grifa a palavra e pergunta.

27-Apaga as letras erradas. 
28- Al : E tem muito $U$.

29-Als: Tem que tirar o U [.......]

30-P: Tirar o U? Apagar o O e deixar o U?

31-Als: Não, o U , professora.

32-Al : Deixar o O (ossu)

33- P: E agora?-----

34-Als: Tirar o U e colocar o O professora. [......]
28- Esse aluno faz referência à escrita da frase toda: $U$ TOTÓIOOSU. 31 Ênfase na entonação da letra $U$. 33-A professora pergunta substituindo a letra $U$ da palavra OSSU pela letra $O$.

35- P: Peraí: se vocês falarem todos ao mesmo tempo eu vou entender?

36- P: Colocar no lugar do $\mathrm{U}$ a letra (....)

37- Als: ÓÓó!!!

38- P: A gente fala OSSU mas escreve OSSO. Lucas, entendeu?

35-A professora retoma a atenção dos alunos, pontuando a questão da indisciplina.

39-Jul: Professora, o I também tá errado.

40-P: Aonde?

41-Jul: Ah o I aí, ó.

42-P: Ah, eu sei, o I. Que que tem o I?

43-Als : Tirar o I e por o E. [.....]

44-P: Tirar o I e por o E.

45-P: Com acento? Se puser o acento fica como?

46-Als e $P$ : O totó é o osso. [......]

47-P: É isso que você quer dizer? O totó é osso?

48-Weder: Não.

49-Al: Professora, tá errado o OSU.

50-P:Vamos ler primeiro. Weder, Weder que fez não foi?

51-Als: Fooi.

52-Al: Tá faltando o 0

53-Outro Al: tá faltando o $\mathrm{N}$.

54-P: Peraí: O TOTÓ tá certo? E CAMIA?

44-Professora repete a fala dos alunos, substituindo as letras 47--Dirigindo-se ao aluno que escreveu o texto.

49-A professora escreve a primeira frase do texto: $O$ TOTÓ, CAMIAE, ASA UMOSU. 50-A professora pede para Weder ler a frase. $O$ aluno lê e ela depois faz a leitura sozinha em voz alta e de forma pausada.

55-Als: Nããão.

56-P: Que é que tem?

57-Al: $\mathrm{O} \mathrm{N}$ e o H e o A

58-P: É? Peraí, fala aí pra mim.

59-Als: O N, o NH.

60-P: Ah! CAMINHA. NHA se escreve com o que?

61-Als: $\mathrm{N} \mathrm{H}$ A.

61-Soletrando. 
62-P: Então já tem o CAMI, tá faltando o (...)

63-Als e P: NHA, que é o N H A

64-P: Então vamos consertar lá.

65-P: Caminha e(...)

66-Als: Acha o osso.

67-P: Que é que tem aí?

68-Al: ASSA.

68-Uma aluna vai ao quadro e tenta corrigir a palavra ASHA.

69-P: Ficou assa e o que que é? 69-Professora escreve no quadro o

70- Ala : ACHA

71-Ala : Nãão.

72-P: Como é que é? que a aluna fala: $E$ ASHA.

73-Als : É o CHA

74-P: Mas isso aqui é $C$ ou $S$ ?

75-Ala: C

76-P: Então no lugar do S é o (...)

75- $A$ aluna escreve o $C$.

77-Als: C

78-P: $\mathrm{CH}$ ACHA

79-P: Acha o osso

80-P: Gente, um de cada vez. Vamos deixar o Lucas ver o que tem no OSSO lá. Por que que OSU não tá certo, Lucas?

81-Luc: Por que o (....)

82-P: Hã?

83-Al : Professora porque Weder não pensou.

84- P: Porque Weder não pensou. Muito bem! Na hora 84-Apontando para que foi escrever osso será que ele pensou? Será que a escrita da palavra é com um S? Será que é com dois S? Ele podia ter pensado. Você pensou Weder? Gente, às vezes a gente pensa (...)mas a gente não tá sabendo escrever as palavras todas certas. Aqui em cima, Weder, acho que você não pensou mesmo não, olha.

80--Lê o restante da frase.

OSU, destacando a reflexão como elemento importante .

85- Em seguida a professora chama a atenção dos alunos para a colocação das vírgulas na frase que está sendo trabalhada. 


\section{Uma possibilidade de análise}

O problema proposto para a turma - reescrever ortograficamente o texto de um aluno, de forma coletiva - mobiliza a participação dos alunos e possibilita a construção de um conhecimento compartilhado (Edwards e Mercer 1988), relacionado às normas e convenções do sistema de escrita. De natureza complexa, a tarefa exige do aluno um esforço deliberado de atenção para a compreensão das relações oralidade-escrita, suas semelhanças e diferenças. Ao longo do episódio, a professora trabalha no sentido de explicitar e problematizar as hipóteses que os alunos têm acerca da ortografia da língua, procurando introduzir novos elementos que possibilitem a sistematização desse conhecimento. Ao que parece, a professora tem consciência do seu papel de conduzir o processo de construção do conhecimento dos alunos e da assimetria constitutiva das relações professor-aluno.

Para analisar o episódio transcrito, vamos subdividi-lo em três partes, de acordo com a forma como a tarefa foi-se estruturando no decorrer da aula.

\section{Primeira parte: a escolha do texto e a apresentação da metodologia}

A professora inicia a aula apresentando uma justificativa para a escolha do texto a ser trabalhado naquele dia e o faz retomando o acordo feito anteriormente com o grupo (turnos 1 a 10) :

Eu vou ler uma que foi a que eu escolhi. Que que eu falei pra vocês? Durante o ano vou "passar" uma de cada um de vocês no quadro. Tem jeito de passar todas de uma vez? (t. 3)

Essa preocupação em rememorar ou recapitular algo que a turma já conhece tem como função garantir a continuidade do trabalho, tomando como referência um contexto comum de compreensão já estabelecido anteriormente (Edwards e Mercer op. cit.). Além disso, a professora introduz alguns elementos da metodologia de trabalho que será utilizada naquela aula, provavelmente já conhecida do grupo.

Percebe-se que o discurso da professora não possui um tom de arbitrariedade ou de imposição de normas, na medida em que procura resgatar algo que já foi negociado anteriormente, num movimento de interlocução com os alunos. 
Dois argumentos importantes são utilizados para justificar a escolha de apenas um texto: o tempo institucional e a necessidade de manter o interesse da turma na tarefa:" primeiro que eu vou ficar atrasada e segundo que vai perder a graça"(t. 7). Nos turnos 8 e 10, dois alunos parecem incorporar a voz da professora, apresentando indícios de internalização da dimensão que o tempo institucional ocupa no processo de ensino-aprendizagem. Esse aspecto é importante pois aponta que os alunos não internalizam apenas conhecimentos nas salas de aula, mas também papéis e relações sociais e institucionais. O tempo é uma preocupação da instituição escolar, que eles de alguma forma internalizaram por força de essa preocupação aparecer com uma certa constância no discurso da professora.

Analisando a fala da professora, percebemos que, nessa mesma seqüência (turnos 1 a 10), ela tem como principal objetivo confirmar a existência de um grau de intersubjetividade através de significados e regras supostamente compartilhados e internalizados pelo grupo, apontando a direção da aula. Ou seja, a professora tem a preocupação de recuperar com os alunos as normas e regras antes discutidas e estabelecidas para o desenvolvimento das aulas de correção coletiva de textos. Trata-se de um dos momentos iniciais de explicitação/retomada das regras de organização do trabalho que será desenvolvido naquele espaço de tempo.

\section{Segunda parte: a explicitação dos papéis de cada um no desenvolvimento da tarefa}

A segunda parte do episódio (turnos11 a 18) é marcada pela tentativa da professora em estruturar a tarefa, no sentido de discutir as formas de participação dos alunos no processo de correção da ortografia do texto. "Enquanto eu tô escrevendo cês vão fazer o quê?" (t.13). "Ler com atenção e observar o quê?" (t.16). O "conteúdo referencialmente semântico do discurso"2 (Bakhtin, 1996) ou o foco de atenção do seu discurso é a tarefa e a metodologia de trabalho, diferentemente dos tópicos anteriores que têm como referente a justificativa para a escolha do texto a ser corrigido, tendo em vista regras negociadas anteriormente.

Nesse movimento discursivo, percebe-se que a professora está dirigindo a atenção dos alunos para os aspectos ortográficos da escrita, evidenciando-se a função reguladora da fala. $O$ padrão discursivo que predomina é o do tipo IRF (iniciação, resposta e feedback), que possibilita a elaboração dos alunos e apresenta, em alguns momentos, (turnos16 e 17), uma dimensão avaliativa na fala da professora. Ela ignora a resposta dos 
alunos "observar a história" (t.16) e propõe "observar o que tá errado"(t. 17). Essa tensão entre a resposta dos alunos e a proposta da professora revela a dinâmica das interações na sala de aula, marcada pelas relações de poder entre a voz da professora e a dos alunos. "Observar a história" e "observar o que tá errado" são dois movimentos diferentes, um mais centrado no conteúdo e outro mais centrado na forma do texto. Podemos dizer que ocorre, nesse momento, um certo conflito ou uma não coincidência entre o que está previsto na agenda ou no planejamento da professora e o que os alunos interpretam como tarefa. Nessa aula, o que está previsto é a correção da ortografia e não a discussão da história como apontam os alunos. A professora resolve a questão assimetrizando sua relação com os alunos, assumindo um discurso de autoridade, que significa ignorar a contribuição do aluno no turno 16 e direcionar a atenção do grupo para os aspectos ortográficos do texto.

O gênero escolar materializa-se, nesse fragmento, num texto de instruções para a tarefa, adequado, portanto, a uma das funções da professora que é a de oferecer as instruções no sentido de possibilitar o desenvolvimento das tarefas propostas. Uma das características do discurso instrucional utilizado pelo professor está relacionado ao fato de que as perguntas do professor não buscam informação, mas têm como função controlar o processo de significação em curso.

Terceira parte: 0 desenvolvimento da tarefa

A terceira parte do episódio (a partir do turno 19) dá início à sistematização das questões da escrita relacionadas à sua forma ortográfica. A professora estabelece, ao longo de todo o episódio, uma problematização dos aspectos ortográficos do texto, criando um contexto que possibilita a explicitação das hipóteses dos alunos sobre a ortografia da língua (ver, por exemplo, turnos $22,24,42,45,47)$. Com essa estratégia, ela vai apontando e nomeando as letras como instrumental necessário e convencional para se "dizer as coisas por escrito". Desse modo, ela vai informando sobre o lugar que as letras ocupam nas palavras e esclarecendo sobre o "valor" sonoro das letras em seus respectivos lugares. Todo o processo desenvolve-se no plano intermental, com a participação oral de uma grande parte dos alunos. Ou seja, a discussão é realizada conjuntamente entre alunos e professora, num contexto em que as dúvidas, as incompreensões, os conflitos e as hipóteses são socializadas e transformadas coletivamente, favorecendo a internalização das formas gráficas pelos alunos. 
A discussão é desencadeada a partir da ação de um aluno que aponta para a grafia da palavra OSU (osso) (presente no título do texto: U TOTÓ I O OSU), referindo-se à ausência do SS em osso e à letra U, colocada no final da palavra osso. Inicia-se então, uma seqüência elicitativa ${ }^{3}$ por parte da professora, no sentido de explicitar as hipóteses sobre a grafia dessa palavra (turnos 19 a 26): "O quê que tá errado?"(t.24). Os alunos respondem corretamente(t.25), mas a legitimidade da resposta é dada quando a professora faz uma síntese no t.27 e afirma: vou por os dois SS aqui", evidenciando-se, assim, a autoridade do professor no processo de ensinoaprendizagem. O feedback da professora é avaliativo e, conforme Edwards e Mercer (op. cit.), esse tipo de resposta tem a função de confirmar ou não a resposta dos alunos e, ainda, de redimensionar o que eles dizem em uma forma autorizada pelas convenções do sistema em questão.

Observamos na seqüência 19 a 33, no turno 54 ("O Totó tá certo? E camia?"); no turno 60 ("Ah! Caminha. NHA se escreve com o quê?"); e no turno 64 ("Então vamos consertar lá"), uma tensão entre univocidade e dialogicidade de acordo com as distinções estabelecidas por Lotman (op. cit.). Isso é evidenciado pelo fato de haver uma alternância entre perguntas de natureza elicitativa $(19,20,24,54,60)$ e avaliativa $(27,64)$, na medida em que a intenção da professora é dar continuidade ao processo de problematização que foi desencadeado sobre a grafia das palavras.

Poder-se-ia dizer que ocorre nesse episódio uma situação em que os alunos que já dominam as regras sugerem hipóteses, o que talvez facilite a internalização dessas regras por outros que não o fizeram ainda. A professora procura direcionar o processo de aprendizagem elegendo a dialogia como um princípio pedagógico, possibilitando a construção da sala de aula como um espaço polifônico constituído por diferentes vozes que se materializam nas diferentes hipóteses oferecidas pelos alunos. O objetivo é fazer com que os alunos produzam grafias de acordo com o modelo convencional do sistema de escrita. Nesse sentido a aparente dialogia que caracteriza o processo tem por objetivo alcançar uma univocidade em torno desse modelo, que é único e não está aberto ao diálogo, mas deve ser aceito em bloco.

No turno 26, um aluno inicia a discussão da letra $U$ no final da palavra OSSU. Percebemos que a professora ignora essa ação do aluno, provavelmente porque está preocupada em trabalhar uma questão ortográfica a cada vez. No turno 28 outro aluno reinicia essa problematização sobre a letra $\mathrm{U}$, referindo-se à frase como um todo (U TOTÓ I O OSSU): e tem muito $U$. Sua intervenção é reforçada por várias falas simultâneas: tem que tirar o U (t. 29). Edwards e Mercer (1988) afirmam que no padrão discursivo do 
tipo IRF predomina a iniciação do professor, uma resposta do aluno e um feedback avaliativo do professor. Nos dados aqui analisados percebemos que essa estrutura se altera, na medida em que os alunos também iniciam as discussões. Outra alteração refere-se às perguntas elicitativas do professor (turnos 19, 20 e 24), que têm a função de possibilitar a continuidade da elaboração conceitual do sistema ortográfico. Ou seja, nem sempre a preocupação do professor é estabelecer uma avaliação ou realizar sínteses e, mesmo que o faça, a preocupação central é permitir o contexto de construção de um conhecimento compartilhado pelo grupo, em direção à transformação dos conceitos da língua escrita pelos alunos.

No turno 38, é evidente a postura de autoridade da professora, no sentido de possibilitar a estabilização dos significados que estão sendo construídos coletivamente, na análise das relações oralidade-escrita, o que implica a distinção grafema-fonema, mas, sobretudo, na diferença entre falar e escrever. Essa característica de autoridade do discurso é também sinalizada pelo aspecto expressivo do enunciado (Bakhtin 1996), que carrega um tom bastante assertivo, sintetizando toda a discussão anterior: "a gente fala ossu mas escreve osso. Lucas, entendeu?". O uso da expressão "entendeu?", além de evidenciar o caráter de autoridade do discurso, demonstra a tentativa da professora de envolver esse aluno no processo, o que a faz chamálo pelo nome. Ou seja, a questão aqui vai além do caráter disciplinar. A fala da professora tem também o significado de um comentário metacognitivo sobre os procedimentos de escrita, envolvendo a explicitação da hipótese que levou à correção do texto - diferença oralidade-escrita - em oposição à hipótese do aluno que produziu o texto - escreve-se como se fala, que pode ser a hipótese de muitos dos alunos e não só do Weder.

O conjunto dos dados coletados na pesquisa (Macedo 1998) demonstra que o Lucas ocupa um lugar diferenciado em relação à turma, o que podemos constatar pelas várias vezes em que a professora recorre a ele nos episódios aqui analisados. Segundo a professora, o Lucas "é a antena da aula. Quando ele não consegue prestar atenção no que está sendo discutido é porque a aula está ruim mesmo". Isso evidencia a presença de um movimento da professora de reconhecimento da importância do outro (seus alunos) na condução e no desenvolvimento dos processos de ensino. Ou seja, o aluno é visto como parte do processo e por isso mesmo pode atuar como regulador da atividade pedagógica.

Um indício de internalização de marcas específicas do discurso escolar pelos alunos pode ser observado nos turnos 52 a 63, quando constroem a 
grafia da palavra caminha utilizando a estratégia de soletração. Ou seja, podemos inferir que, além da grafia das palavras, os alunos também parecem internalizar as estratégias de análise utilizadas pela professora. Além disso, Smolka nos indica que

(...) quando a professora soletra as palavras e mostra as letras do alfabeto, ela está destacando, apontando e nomeando elementos do conhecimento para a criança e indicando uma forma de organização deste conhecimento. Quando a criança fala, pergunta ou escreve, é ela quem aponta para a professora o seu modo de perceber e de relacionar o mundo. Nessa relação, o conhecimento se constrói. (1988, p. 43)

No decorrer das discussões sobre os aspectos ortográficos do texto, percebemos outros elementos que vão constituindo a dinâmica discursiva. A professora chama a atenção para as conversas simultâneas e a função do seu discurso é "controlar" a disciplina: "peraí, se vocês falarem todos ao mesmo tempo eu vou entender?(t. 35). Mas essa professora usa o gênero de discurso disciplinar também como um modo de compartilhar as estratégias de organização do trabalho na sala de aula, uma vez que sua fala remete a uma regra que deve ter sido negociada previamente: um aluno falando de cada vez. A mudança no gênero de discurso é evidenciada pela alteração no conteúdo referencialmente semântico do discurso (da discussão da ortografia passa-se à discussão da disciplina), o que ocorre também no turno 80. Esse tipo de discurso tem uma função claramente unívoca e é marcado principalmente por um tom de voz diferenciado do até então utilizado. Além da alteração do conteúdo semântico do discurso (da ortografia para a disciplina) altera-se também a relação entre os interlocutores, na medida em que a intenção da professora parece ser a de demandar uma certa fidelidade do aluno ao que está sendo colocado como norma e estratégia: a necessidade de um falar a cada vez para que todos sejam ouvidos.

No turno 45, a professora propõe a discussão da acentuação gráfica, problematizando a escrita da palavra é: "com acento? Se puser acento fica como?" Com essa postura, fica evidente o papel da professora na condução do processo de ensino, que é o de introduzir novos elementos para os alunos pensarem, possibilitando a transformação dos processos individuais. Ela o faz num momento significativo, pois a questão do acento é retirada do texto do aluno e não proposta arbitrariamente ou artificialmente .

Além disso, a professora recorre por duas vezes ao autor do texto, como um mediador explícito do processo de construção coletiva das rela- 
ções fala e escrita : "é isso que você quer dizer? O totó é osso?" (t.47); "Vamos ler primeiro. Weder, Weder que escreveu, não foi?" (a professora pede para 0 autor fazer a leitura da frase - t.50). Essa estratégia sugere que, além da preocupação com os aspectos formais do texto, a professora também pontua a questão da autoria, característica do gênero do qual eles estão se apropriando, o texto escrito.

Observamos outra mudança no referente do discurso no turno 83, quando um aluno argumenta que o erro na escrita da palavra osso (osu) ocorreu em função do autor do texto não ter pensado no momento da escrita da palavra: " professora, porque Weder não pensou". Observa-se aqui o eco da voz da professora, que normalmente utiliza esse tipo de comentário durante as aulas. A professora concorda com a resposta do aluno, discutindo-a de forma bastante enfática no t.84: "...porque Weder não pensou. Muito bem! $\mathrm{Na}$ hora que foi escrever osso será que ele pensou? Será que é com um S? Será que é com dois S? Ele podia ter pensado. Você pensou Weder? Gente, às vezes a gente pensa (...)mas a gente não tá sabendo escrever as palavras todas certas. Aqui em cima, Weder, acho que você não pensou mesmo não, olha".

Ao que parece, a professora aproveita o comentário de um aluno para direcionar a atenção da classe para a importância de uma postura reflexiva frente ao sistema ortográfico da língua, na medida em que esse é um objeto de natureza conceitual e exige, portanto, que o aprendiz analise e reflita sobre suas especificidades. Aqui, mais uma vez, tem-se uma evidência de que a postura da professora possibilita o espaço para que os alunos iniciem certas seqüências, oferecendo temas para a discussão que na maioria das vezes refletem um eco da própria voz da professora.

Esse tipo de comentário sobre os processos cognitivos aparece também no início do episódio, mais especificamente no turno 15, em que a professora orienta os alunos para a leitura do texto. De acordo com a orientação, a leitura deverá ser feita com atenção e os alunos deverão fazer a observação dos erros ortográficos do texto. São comentários metacognitivos cuja principal função é chamar a atenção dos alunos para o papel das funções mentais no processo de construção do conhecimento, neste caso reforçando o papel da atenção voluntária (Vygotsky 1991).

Esses comentários foram constatados também por Edwards e Mercer (1988) em suas pesquisas sobre as interações na sala de aula. De acordo com os autores, o professor faz comentários metacognitivos e metadiscursivos quando percebe que algum aluno ou alguns alunos estão com dificuldades 
de compreensão do que está sendo discutido. No entanto, no episódio analisado, constatamos que os comentários metacognitivos do início da aula tiveram como objetivo orientar ou instruir os alunos para a realização da tarefa. Destacamos aqui a função reguladora da linguagem materializada na fala da professora. O comentário do turno 84 sobre a possível falta de reflexão do aluno na escrita da palavra osso (ossu), pode ter sido feito a partir da constatação de uma dificuldade dele na elaboração dos aspectos ortográficos da escrita.

O importante a ser destacado é que os comentários metacognitivos e metadiscursivos não são realizados apenas quando se constata uma dificuldade do grupo, mas, também, quando se tem a intenção de conduzir e orientar os alunos para uma determinada postura frente às atividades. Dessa forma, eles são guiados pela necessidade de explicitar aspectos importantes para a negociação não só de significados mas também de regras e de relações que criam um espaço intersubjetivo. A negociação desse espaço, no entanto, faz-se sempre a partir do ponto de vista da professora e da função da escola.

\section{Algumas considerações finais}

A análise desse episódio teve como principal objetivo compreender como os processos de ensino-aprendizagem da língua escrita ocorrem na dinâmica discursiva da sala de aula.

Vimos que o processo de apropriação do conhecimento formal dáse no contexto de determinadas relações de ensino, sendo constituído e transformado por elas. Na apropriação da escrita, constatamos que a criança constrói esse conhecimento pela mediação do professor e dos próprios colegas, num processo marcado pela tensão e contradição, constitutivas das interlocuções na sala de aula, e pelo envolvimento significativo dos alunos com o conhecimento.

O episódio permite-nos inferir que o discurso da professora, nessa sala de aula, é, ao mesmo tempo, um discurso unívoco e dialógico, porque possibilita que as vozes dos alunos sejam parte constitutivas do processo de enunciação, contribuindo, assim, para a elaboração de significados pela criança, mas, ao mesmo tempo, tem por objetivo a construção de um sistema único de regras ortográficas, portanto unívoco e não sujeito a alterações. Isso nos permite supor que o discurso pedagógico é, apenas na sua aparência, autoritário e homogêneo. Trata-se de um discurso que convoca a participação do grupo sem, contudo, deixar de exercer o controle dos processos de ensinoaprendizagem, visto que o lugar social que a professora ocupa lhe autori- 
za a agir dessa forma, o que implica em pensar a relação professor-aluno como uma relação fundamentalmente assimétrica.

As situações de ensino-aprendizagem apresentadas apontam-nos a "dimensão interdiscursiva" e a importância da relação dialógica no trabalho simbólico de escritura, ou seja, a emergência da "escritura como prática discursiva" (Smolka 1988).

Dessa forma, podemos inferir que as condições de produção do conhecimento, nessa sala de aula, favorecem a internalização da compreensão da natureza da língua escrita pelos alunos. Como pressupõe Vygotsky (1991), a construção do conhecimento ocorre primeiro no plano intermental, para depois se constituir no plano intramental. Os processos de ensino aqui analisados, de certa maneira, representam essa dinâmica, na medida em que toda a discussão das questões relativas aos aspectos ortográficos da língua escrita foi conduzida pela professora de maneira dialógica, num espaço coletivo que buscou favorecer a troca sistemática, a explicitação e o conflito entre diferentes hipóteses, a problematização e a socialização de dúvidas e questões dos alunos. Toda a discussão constitui-se na base para a elaboração de sínteses pela professora, no sentido de propiciar a transformação do conhecimento, favorecendo a internalização da língua escrita e das diferentes vozes que constituem o gênero escolar pelos alunos. Um indício significativo que caracteriza essa postura da professora está relacionado ao fato de os alunos também iniciarem os turnos de fala nos momentos das discussões coletivas. Ou seja, na dinâmica discursiva percebemos que o aluno toma a iniciativa de introduzir questões e de problematizá-las e sua fala, como a da professora, exerce a função de regulação dos processos de ensinoaprendizagem da turma.

Outro indício importante está relacionado à natureza das perguntas da professora ao dirigir-se aos alunos: diferentemente do que Edwards e Mercer (1988) apontam, a professora responde aos alunos não apenas para avaliar suas respostas, mas, também, para introduzir elementos que possibilitem a problematização, a reflexão e a elaboração da escrita. Na sua fala são constantes as perguntas elicitativas que têm por objetivo buscar compreender as hipóteses que os alunos estão construindo sobre a ortografia. Nesse sentido, os erros são compreendidos por ela como hipóteses de trabalho no processo de elaboração conceitual da língua escrita pelos alunos.

O tempo institucional é uma questão que atravessa a dinâmica discursiva, condicionando os processos de ensino-aprendizagem nessa sala de aula. A ansiedade da professora na forma de lidar com essa questão evidencia 
um conflito vivenciado por ela: dar voz aos alunos, contemplando, no planejamento curricular, os diferentes processos de aprendizagem, por um lado, e trabalhar com um limite imposto pelo tempo institucional, que organiza e condiciona os processos de ensino-aprendizagem na escola, por outro.

Percebemos que, embora a professora busque um equilíbrio na relação planejamento/processo, essa busca evidenciará, necessariamente, conflitos e contradições, na medida em que, em muitos momentos, o que predomina é a voz do professora em detrimento da voz do aluno, ainda que na voz da professora estejam materializadas as vozes dos alunos. Parece evidente, ainda, que os alunos internalizam não só o conteúdo do discurso da professora, materializado nas regras ortográficas, mas também regras disciplinares e aspectos metacognitivos do aprendizado, como por exemplo a idéia de que é necessário pensar para se escrever, manifesta por um aluno no turno 83. Isso mostra que a pressão em direção à univocidade parece predominar no discurso escolar. Apesar de admitir a interanimação de vozes nos processos de significação, a escola sinaliza que esses processos têm por objetivo um discurso unívoco e de autoridade, aqui representados pelas regras ortográficas (que são únicas), pelas regras disciplinares (que apesar de previamente negociadas são para serem seguidas) e de comportamento (por exemplo, pensar para escrever, que também são para serem seguidas). A forma bastante natural como os alunos respondem a essa pressão em direção à univocidade, apropriando-se da voz da professora, evidencia que a intersubjetividade é negociada na sala de aula sempre do ponto de vista da professora e que esta regra é implicitamente assumida por todos participantes.

As características sobre a dinâmica discursiva nessa sala de aula aqui apontadas apresentam algumas implicações pedagógicas. Uma primeira implicação está relacionada à necessidade de repensarmos a concepção de currículo que tem norteado a prática escolar, o que significa compreender o currículo para além de procedimentos metodológicos e conteúdos conceituais. Nessa perspectiva o currículo é compreendido como um conjunto de elementos "ditos e não ditos" da cultura escolar que condicionam as relações de ensino na sala de aula, o que pode possibilitar a incorporação da cultura e do desenvolvimento do sujeito como partes constitutivas do processo de ensino-aprendizagem.

Outra implicação, relacionada à primeira, refere-se à importância de aprofundarmos a compreensão da dialogia como um elemento constitutivo dos processos de ensino, para que tenhamos uma escola que possibilite aos alunos o exercício da argumentação no processo de elaboração conceitual através da mediação do professor. 
A importância atribuída à ortografia pelos alunos, evidenciada pelo nível de envolvimento e pela qualidade de sua participação na discussão dos aspectos ortográficos da escrita, não foi construída espontaneamente e pode estar relacionada, entre outras coisas, à forma como o processo de aprendizagem foi conduzido pela professora, a partir de uma postura dialógica e do direcionamento dos alunos para o exercício da atenção voluntária ao sistema de escrita. Isso evidencia o lugar da interação nos processos de ensino do sistema ortográfico e rompe com a centralidade do professor nesse processo. Nesse sentido, apontamos a importância da escola repensar o lugar que o professor tem ocupado no processo de ensino-aprendizagem e a concepção de língua com a qual tem trabalhado, geralmente considerada como um código abstrato desvinculado de suas funções sociais, em que os exercícios estruturais são utilizados como estratégia metodológica predominante.

\title{
Notas
}

1. Entre eles Edwards e Mercer (1988), Hickman e Werstch (1978), Fontana (1996) e Smolka (1997).

2. Bakhtin aponta a forma genérica como uma das características do enunciado. A escolha do gênero é determinada por três fatores: a composição pessoal dos falantes, o conteúdo temático (ou referencialmente semântico) e o aspecto expressivo do enunciado.

3. O termo elicitativa é utilizado por Mortimer e Machado (1997). Consideramos elicitativas as perguntas da professora dirigidas aos alunos com o objetivo de identificar as questões, dúvidas e hipóteses desses sobre o objeto de conhecimento que está sendo problematizado.

Recebido para publicação em Agosto de 2000.

\section{The discurcive dinamics in the classroom and the writting appropiation}

\begin{abstract}
This article analyzes, in the context of the sociocultural theory, aspects of the discursive dynamic of a classroom in which writing and orthographic rules were taught. The data were recorded in video and the transcriptions, organized in teaching episodes, were submitted to microgenetic analysis. From the analysis it can be inferred that the teacher discourse is heterogeneous since it lets the students participate in the process of enunciation and, at the same time, controls the production of univocal meanings related to the orthographic rules. The data also indicate that students internalize not only the teaching contents but also more general aspects of the school discourse, as disciplinary rules and metacognitive strategies of learning.
\end{abstract}




\section{Bibliografia}

BAKHTIN, M. Marxismo e Filosofia da Linguagem. $7^{a}$ edição. São Paulo: Hucitec, 1929/1995.

. Estética da Criação Verbal. 2ª edição. São Paulo: Martins Fontes, 1975/1996.

EDWARDS, D. e MERCER, N. El conocimiento compartido: El desarrolo de la comprensión en el aula. Buenos Aires: Paidós, 1988.

FONTANA, R.A .C. A mediação pedagógica na sala de aula. Campinas: Autores Associados, 1996.

MACEDO, M. do S.A.N. "A dinâmica discursiva na sala de aula e a apropriação da escrita”. Dissertação de Mestrado. Faculdade de Educação, UFMG. Belo Horizonte, 1998.

MORTIMER, E.F. e MACHADO, A.H. "Multivoicedness and univocality in classroom discourse: An example from theory of matter". In: INT.J.SCI.EDUC., 1988, oㅜ 1, vol.20, pp.67-82.

. "Múltiplos olhares sobre um episódio de ensino: Por que o gelo flutua na água?" Anais do Encontro Linguagem Cultura e Cognição: Reflexões par o Ensino de Ciências. UFMG. Belo Horizonte, 5 a 7 de março de 1997, pp. 139-162.

ROMMETVEIT, R. "On the architecture of intersubjectivity". In: ROMMETVEIT R. e BLAKAR R.M. (eds.), Studies of language, thought, and verbal communication. London: Academic Press, 1979, pp. 93-108.

SMOLKA, A.L. A criança na fase inicial da escrita: Alfabetização como um processo discursivo. São Paulo: Cortez, 1988.

VYGOTSKY, L.S. A formação social da mente. 4ª edição. São Paulo: Martins Fontes, 1991.

WERTSCH, V.J. Voces de la mente: Un enfoque sócio-cultural para el estudio de la acción mediada. Madrid: Visor, 1991.

.Vygotsky y la formación social de la mente. Buenos Aires: Paidós, 1988.

WERTSCH, J. e SMOLKA, A. L.B. "Continuando o diálogo: Vygotsky, Bakhtin e Lotman". In HARRY, D. (org.) Vygotsky em foco: pressupostos e desdobramentos. Campinas: Papirus, 1994 